\title{
CATION EXCHANGE CHROMATOGRAPHIC SEPARATION OF AMINES THROUGH FIBER SUPPORTED SOLID MEMBRANE
}

\author{
A. G. Gaikwad* \\ CE E PD Division, National Chemical Laboratory, Pune 411008, India
}

Received 08 January 2011; accepted 05 September 2011

\begin{abstract}
The cation exchange chromatographic separation of pyridine, monoethanol amine (MEA) and triethanol amine (TEA) have been explored from source to receiving phase through a fiber supported solid membrane (FSSM). The FSSM were prepared by chemical modification of cellulose fibers with introducing the carboxylic acid ion exchanging groups. The experimental values explored were concentration of pyridine, MEA and TEA $\left(10^{-2}\right.$ to $\left.10^{-6} \mathrm{M}\right)$ in the source solution, $\mathrm{HCl}(0.01$ to $0.20 \mathrm{M})$ in the receiving phase and stirring speed (50$130 \mathrm{rpm}$ ) of the bulk source and receiving phase. The efficiency of FSSM has been evaluated for the transport of pyridine, MEA and TEA from the source to receiving through membrane phase. The enrichment factors (EF) for pyridine, MEA and TEA from the dilute solutions such as $10^{-6} \mathrm{M}$ observed were 1.62, 2.26 and 1.7, respectively.
\end{abstract}

Keywords: Pyridine, monoethanol amine (MEA), triethanol amine (TEA), fiber supported solid membrane (FSSM), ion exchange

DOI:10.3329/cerb.v15i1.6788

\section{Introduction}

The amines are used, as a solvents and intermediates, in agricultural chemicals, drugs, dyestuffs, paints, rubber products, polycarbonate resins, textile water repellents and laboratories. Pyridine, MEA and TEA are found to be contaminated in several materials. Therefore, there is need to develop the separation methods for these amines.

The porous solid polymers and inorganic support materials have gained additional advantages in the selective separations by molecular recognition based on template imprinted mechanism [1-5]. The monolithic stationary phases are used in the high performance liquid chromatography (HPLC) due to their ease of preparation, reproducibility, versatile surface chemistries, selectivity and fast mass transport [6-10]. A novel method preparation of chromatographic stationary phases of polymeric or fibers eliminates the polymeric material grinding, sieving, column packing and the high back pressures $[11,12]$. The chemically modified fiber of synthetic polymer or of natural made could be directly used as solid membrane phase. Through porous solid fibers, the transport mechanism is very fast, selective and effective for the separation and detection purposes. The fibers have been used as stationary phase in the capillary electro-chromatography for the separations [13]. The direct coupling of the extraction process with liquid

* Corresponding author Email: ag.gaikwad@ncl.res.in Ph: 020-2590-2164 Fax: 020-2590-2612 chromatography has been used for the analysis of nbutylphthalate in wastewater [14]. The different agricultural residues such as wheat straw, bagasse, cotton stalks, and saw dust have been chemically modified to prepare cation exchangers [13-17]. The cellulose ion exchangers were prepared by attaching substituent groups to the cellulose fibers, usually by etherification or esterification reactions. Although, chemically modified cotton fibers are similar to ion exchange properties of resins, they are much fine, porous fiber, have larger surface area and the capillary action of the fine fibers have the enhanced absorbing power of liquid The modified cotton fibers porous structure permits the rapid entrance and diffusion of liquid phase [18-23]. The porous fibers of polyester or polyamide (nylon) or cellulose depending on the chromatographic applications can be used. The cellulose porous micro fiber can absorb up to seven times its weight in fluids [24]. The cellulose porous micro fibers are also extremely durable can be washed up several times and maintain their effectiveness. The cellulose fibers have hydroxyl groups with low dissociating power and weak in acidic properties. Therefore, the fixing of solid or liquid membrane phase over cellulose fibers is an essential for the selective transport of the ions through the cellulose fibers. Citric or tartaric acid could be esterified over the cellulose fibers which could be used as FSSM [18-23]. In these investigations, FSSMs were used for the transports of amines from the source to receiving phase. The advantages of FSSM are no loss of solvent, flow rate of 


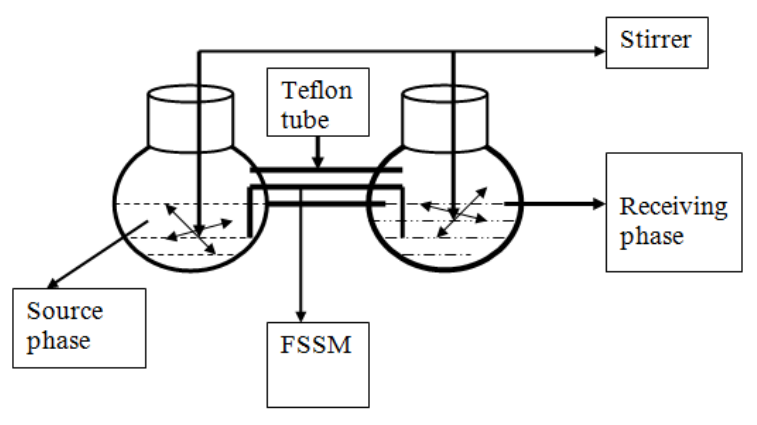

Figure 1: The schematic presentation of FSSM cell

source and receiving phase could be controlled, desired solid membrane phase could be chemically attached to the fibers for the selective separations. The FSSM technique is useful for selective removal of the desired product from the reaction mixture by using selective receiving phase. In this paper, the transport mechanisms of amine have been illustrated through the FSSM. The research studies included the experimental variables as concentration of amine in source and acid in the receiving solutions.

\section{Experimental}

\subsection{Reagents and apparatus}

The aqueous acid solution was prepared from concentrated acids (Merck, India Ltd.,) in distilled and deionized water. Cellulose porous solid fibers obtained from Aldrich Chemicals were used. TEA, MEA and pyridine were used (Aldrich Chemicals CO, USA). The dilute solutions of TEA, MEA and pyridine were prepared from their stock solutions. The concentration of amine (TEA, $\mathrm{pKa}=7.8, \mathrm{MEA}, \mathrm{pKa}=9.5$ and pyridine $\mathrm{pKa}=5.21$ ) in the solution was analyzed by acid base titrations or spectrophotometer determinations or HPLC or gas chromatography (FID) [25-33] depending on the concentrations. The FSSM experimental apparatus used to measure the permeability coefficient (P) (Figure 1). The amine ion concentration with respect to time was determined from the samples drawn from the source and receiving solutions.

\subsection{Synthesis}

The cellulose fibers with dimensions of diameter $0.027 \mathrm{~cm}(270 \mu \mathrm{m})$ and porosity 30 to $50 \%$ were used. The cross section area of porous fibers was $5.73 \times 10^{-4}$ $\mathrm{cm}^{2}$. The adsorbed amount of solution in the fibers was estimated by weighing the fibers before and after the soaking in the aqueous solution. The cellulose fibers were modified by the reaction.

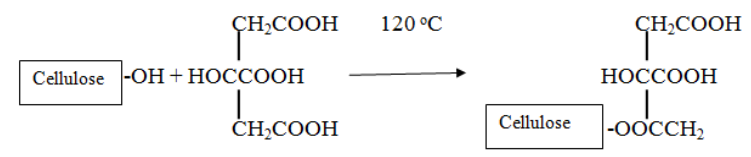

The cellulose fibers were modified by treatment with $0.5 \mathrm{M}$ citric acid in the ratio of $1: 12$ (cellulose fiber: acid, w/v). The reaction mixture was stirred for $30 \mathrm{~min}$. The acid/cellulose fiber slurry was dried in a stainless steel reactor at $50^{\circ} \mathrm{C}$ in a forced air oven for $24 \mathrm{~h}$. The thermochemical esterification was carried out between acid and cellulose fiber by raising the oven temperature to $120^{\circ} \mathrm{C}$ for $90 \mathrm{~min}$. Then, the esterified cellulose fibers were washed with distilled water until free from citric acid (Tested for turbidity with $0.1 \mathrm{M}$ lead (II) nitrate solution). The dried esterified cellulose fibers product was treated by stirring with $0.1 \mathrm{M} \mathrm{NaOH}$ at suitable ratio for $60 \mathrm{~min}$. Then, it thoroughly washed with distilled water to remove free alkali. Then the wet modified cellulose fibers were dried at $50^{\circ} \mathrm{C}$ for $24 \mathrm{~h}$. The modified fibers were preserved in desiccators for further use. Before use, if necessary, the modified cellulose fibers were converted into acidic form with the acid treatment [1517]. The chemically modified fibers are termed as the fibers supported solid membrane (FSSM).

\subsection{Procedure}

The solutions were used of a source solution with a suitable amine concentration in $15 \mathrm{ml}$ in the source compartment of the cell, and the receiving phase $15 \mathrm{ml}$ with appropriate concentration of acid in the receiving compartment of the cell. The source and receiving solutions were connected with FSSM (supported in teflon tube with $0.4 \mathrm{~cm}$ od, id $0.2 \mathrm{~cm}$ ) (Figure 1). The samples of the source and receiving solutions were withdrawn and analyzed.

\section{Results and Discussion}

\subsection{Mechanism of amine transport}

The cellulose fibers due to its hydroxyl group with low dissociating and weak in acidic properties slowly transport the ions through the fibers. Therefore, cellulose fibers were modified by fixing the supported solid or liquid membrane phase for the selective transport of the ions through the source to receiving phase through fiber supported solid membrane. Figure 2 illustrates the transport of amine from source to receiving through FSSM. There is no continuous flow of mobile phase either from source or receiving phase through the FSSM, but, there is a transport of amine from the source solution through the membrane phase to receiving phase. However, the ion exchange mechanism was used during the process of ion transport through the FSSM. The capillary action mechanism in the porous fibers is helpful to maintain the liquid in the fibers during the transport of amine. The fiber supported solid membrane phase is used as the membrane barrier in between source and receiving phase. The transports of amine are occurred through the fiber 


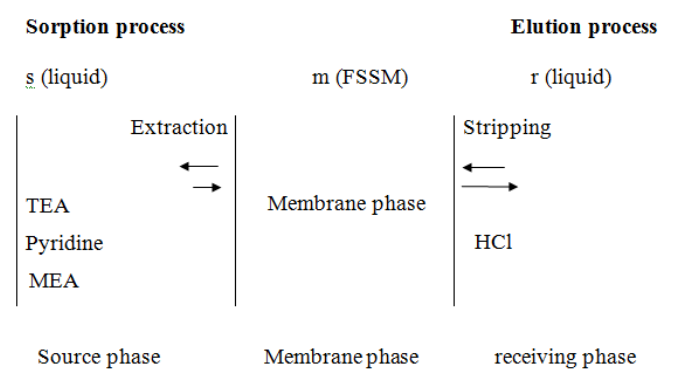

Figure 2: The amine transport through FSSM

supported solid membrane phase because of the difference in gradient concentrations in between source and receiving phase, and also the driving forces of the acid in the receiving phase. The reactions of amines with the fiber supported (fiber supported citric acid) acidic groups and the hydrochloric acid in the receiving phase have been explored for their transport through FSSM.

\subsection{Determination of permeability coefficient}

In the FSSM cell, the rate of change of concentration of amine $\left(C^{s}\right)$ in the source phase with respect to time $(t)$ through a cross section area $(A)$, volume of source phase $\left(V_{s}\right)$ and fibers column membrane phase length $(l)$ can be given by the Equation 1 , where, $k$ is a rate constant.

$$
-d C^{s} / d t=k \cdot A /\left(V_{s} \cdot l\right) \cdot C_{0}^{s}
$$

After integrating the Equation 1, the permeability coefficient $(P)$ of transport of amine is obtained by the Equation 2. In the FSSM system, membrane supports can be used with the design of cross section area to length ratio $(A / l)$, where length, $l$, is increased, while the cross section area, $A$, is decreased. Therefore, in the proposed FSSM system, by increasing the length, $l$, and decreasing the cross section area, $A$, the membrane support becomes a fiber with a long length, $l$, and small cross section area, $A$, (As a fiber with long length and low cross section area $A$ ). The permeability coefficient of transport of amine is expressed by Equation 2.

$$
\ln \left(C_{t}^{s} / C_{0}^{s}\right)=-\left(A / V_{s}\right) \cdot(P / l) . t
$$

where, $C_{0}$ is the value of $C_{t}$ at time zero. The permeability coefficient $(P)$ is calculated from the plots of $\log \left(C_{t} / C_{0}\right)$ vs $t$ (time) by using membrane cross section area $5.73 \times 10^{-4} \mathrm{~cm}^{2}, l \mathrm{~cm}$ length of fibers and source phase volume $15 \mathrm{ml}$. The calculated permeability coefficient $(P)$ is used to interpret the data of transport of amine through porous solid FSSM at different experimental conditions. Porous solid FSSM was used in a teflon tube (with od $0.4 \mathrm{~cm}$ and id $0.2 \mathrm{~cm}$ ).

The fibers supported solid membrane cation exchanger transport amine (TEA, pKa $=7.8, \mathrm{MEA}, \mathrm{pKa}$

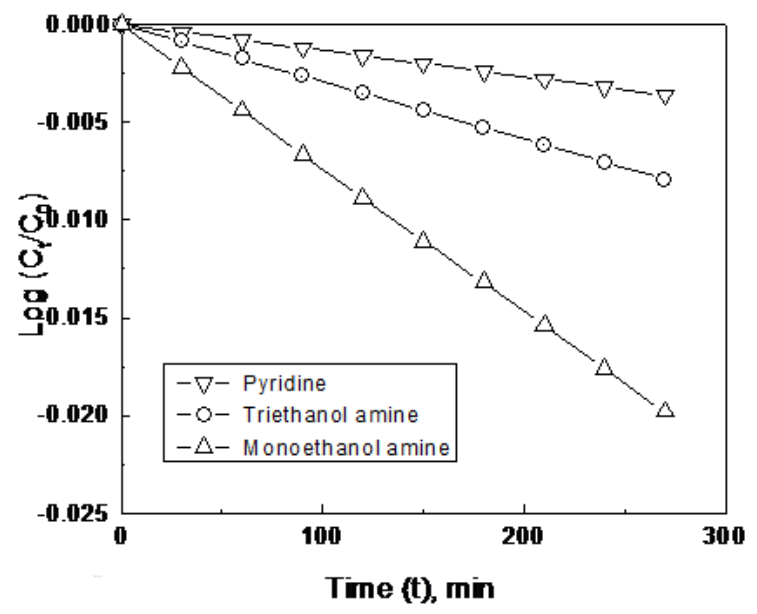

Figure 3: The plot of $\log C_{t} / C_{0}$ vs. time, amine $=0.001 \mathrm{M}, \mathrm{HCl}=$ $0.1 \mathrm{M}$

$=9.5$ and pyridine $\mathrm{pKa}=5.21)$ through quaternary ammonium salt formation mechanism from source solution through membrane phase to receiving phase as presented by following reaction.

$$
\begin{gathered}
\mathrm{Q}_{\mathrm{s}}+\mathrm{R}-\mathrm{COOH}_{, \mathrm{m}} \rightarrow\left(\mathrm{R}-\mathrm{COO}^{-}\right) \mathrm{HQ}^{+}{ }_{\mathrm{m}} \\
\left(\mathrm{R}-\mathrm{COO}^{-}\right) \mathrm{HQ}^{+}{ }_{\mathrm{m}}+\mathrm{HL}, \mathrm{r}
\end{gathered}
$$

\subsection{Amine concentration variation}

The experiments were carried out with the porous solid FSSM. The amine concentration was determined with respect to time. The plots are shown of $\log C_{t} / C_{0}$ vs time $(t)$ in the Figure 3. The $\mathrm{P}$ values were calculated using the slope of the straight line, cross section area $\left(A, 5.73 \times 10^{-4} \mathrm{~cm}^{2}\right)$, and $(l, 4 \mathrm{~cm})$ length of fiber.

\subsection{Fibers length effect}

The plot of $\log \mathrm{P}$ against the length of porous solid FSSM is shown in the Figure 4. The $\log \mathrm{P}$ value decreases with the increase in the length of the porous FSSM. The cause of increased in the path length of the amine transport through the FSSM is the increased length of FSSM.

\subsection{Stirring speed effect}

Stirring of source and receiving bulk solutions is essential in order to achieve the effective diffusion of amine through bulk solution. The source and receiving phases were independently stirred at 50 to 130 $\mathrm{rpm}$. The permeability coefficient $(\mathrm{P})$ was estimated for these stirring ranges. The increase in the $\mathrm{P}$ value was observed for the 50 to $110 \mathrm{rpm}$. This shows that the decrease in the thickness of diffusion layer at the bulk liquid solution and also at the interface of liquid 


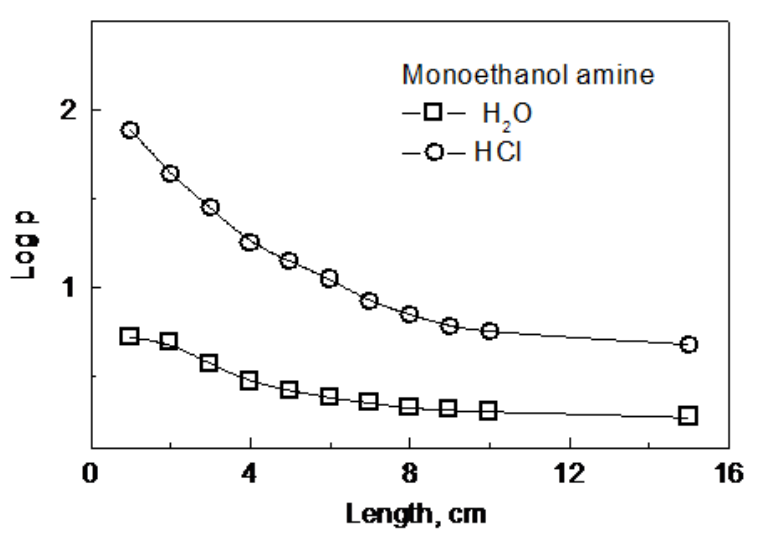

Figure 4: The variation of $\log P$ with respect to FSSM length, amine $=0.001 \mathrm{M}, \mathrm{HCl}=0.1 \mathrm{M}$

Table 1: The $\log P$ values with respect to stirring speed of bulk

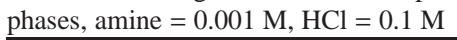

\begin{tabular}{rrrrr}
\hline Sr. No & $\begin{array}{r}\text { Stirring speed } \\
(\mathrm{rpm})\end{array}$ & Pyridine & TEA & MEA \\
\cline { 3 - 5 } & 50 & 0.18 & 0.34 & 0.7 \\
2 & 75 & 0.22 & 0.45 & 0.8 \\
3 & 100 & 0.32 & 0.65 & 0.9 \\
4 & 110 & 0.51 & 0.85 & 1.25 \\
5 & 120 & 0.52 & 0.88 & 1.27 \\
6 & 130 & 0.54 & 0.89 & 1.28 \\
\hline
\end{tabular}

in the porous solid FSSM. The P value nearly remains the same for 110 to $130 \mathrm{rpm}$ (Table 1). This stirring range represents the achievement of minimum diffusion layer thickness at the interface of liquids in the FSSM. Further, research studies were explored at 120 rpm. It was observed that the pyridine was trailed to MEA and pyridine.

\subsection{Acid concentration effect}

The transport of amine through the porous solid FSSM depends on the gradient concentration in the source and receiving phase. The effect of driving forces of acid is explored for the transports of amine from source to receiving phase through the FSSM. The acid concentration in the receiving solution strip out the amine from the carboxylic acid groups from the FSSM (Equation 4). The acid concentration in the receiving solution was varied for 0.01 to $0.2 \mathrm{M}$ (Table 2 ). The increased acid concentration increases the $\log \mathrm{P}$ values for the concentration range 0.01 to $0.20 \mathrm{M}$. The relative sequence of transport of amines in the receiving phase was observed in the increased concentration as MEA > TEA > pyridine

\subsection{Effect of solvent}

The solvent effect has been studied on the cation exchange chromatographic separations of amine. The Figure 5 shows the transport of amines with the variation of solvent in the receiving phase. It was observed that the hydrochloric acid is more efficient than
Table 2: The $\log P$ values with respect to hydrochloric acid concentration in receiving phase, amine $=0.001 \mathrm{M}$

\begin{tabular}{crrrr}
\hline \multirow{2}{*}{ Sr. No } & HCl, mol/l & \multicolumn{3}{c}{$\log P$} \\
\cline { 3 - 5 } & & Pyridine & EA & MEA \\
\hline 1 & 0.01 & 0.16 & 0.44 & 0.82 \\
2 & 0.05 & 0.32 & 0.65 & 1.02 \\
3 & 0.1 & 0.51 & 0.85 & 1.25 \\
4 & 0.2 & 0.76 & 1.1 & 1.48 \\
\hline
\end{tabular}

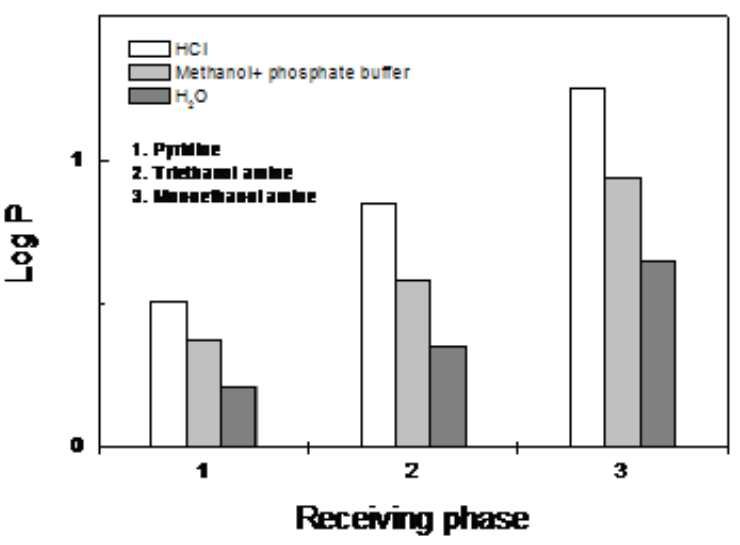

Figure 5: The relation between $P$ and solvent, amine $=0.001 \mathrm{M}$, $\mathrm{HCl}=0.1 \mathrm{M}$

water or methanol- phosphate buffer for the transport of amines from the source to receiving through membrane phase. MEA travelled more rapidly than TEA or pyridine.

\subsection{Hydrophobic and hydrophilic surface effect}

The transports of amine were explored through the porous solid fiber supported in hydrophobic surface of teflon tube (id $0.2 \mathrm{~cm}$ ) and hydrophilic surface of glass tube (id $0.2 \mathrm{~cm}$ ). The results show that the transports of amine through the FSSM in teflon tube are higher than that of glass tube FSSM. The effect hydrophobic surface of teflon and hydrophilic surface of glass tube have on the transports of amine.

\subsection{Enrichment of amine}

The initial concentration of amine in the source solution was varied in the range 10-6 to 10-2 M. The observed enrichment factor (EF is a ratio of amine concentrations at time in the receiving to source phase) with respect to initial amine concentration in source solution is shown in Table 3. The enrichment factor $(\mathrm{EF})$ decreases with increase in the initial amine concentration in the source phase. The enrichment of amine is more effective from its low concentration solution. However, MEA was found more advanced in the receiving phase than TEA or pyridine

\section{Conclusion}

The transports of pyridine, MEA and TEA were investigated FSSM from source to receiving phase. The 
Table 3: The EF (enrichment factor) values with respect to amine concentration, $\mathrm{HCl}=0.2 \mathrm{M}$

\begin{tabular}{rrrrr}
\hline \multirow{2}{*}{ Sr. No } & Log [Amine] & \multicolumn{3}{c}{ EF } \\
\cline { 3 - 5 } & & Pyridine & TEA & MEA \\
\hline 1 & -2 & 1.15 & 1.21 & 1.37 \\
2 & -3 & 1.22 & 1.25 & 1.49 \\
3 & -4 & 1.27 & 1.31 & 1.62 \\
4 & -5 & 1.41 & 1.51 & 1.83 \\
5 & -6 & 1.62 & 1.7 & 2.28 \\
\hline
\end{tabular}

transports of pyridine, MEA and TEA depend on the hydrochloric acid concentration $(0.01$ to $0.2 \mathrm{M})$ in the receiving phase and stirring of bulk phases (50-130 $\mathrm{rpm})$. The enrichment factors observed for pyridine, MEA and TEA were 1.62, 2.26 and 1.7, respectively.

\section{References}

[1] Mahony JO, Nolan K, Smyth MR and Mizaikoff B, Molecularly imprinted polymers-potential and challenges in analytical chemistry, Analytica chimica acta, 2005. 534(1):pp. 31-39

[2] Kindschy LM and Alocilja EC, A molecularly imprinted polymer on indium tin oxide and silicon, Biosensors and Bioelectronics, 2005. 20(10):pp. 2163-2167

[3] Yan H, Row K and Yang G, Water-compatible molecularly imprinted polymers for selective extraction of ciprofloxacin from human urine, Talanta, 2008. 75(1):pp. 227-232

[4] Liu X, Ouyang C, Zhao R, Shangguan D, Chen Y and Liu G, Monolithic molecularly imprinted polymer for sulfamethoxazole and molecular recognition properties in aqueous mobile phase, Analytica chimica acta, 2006. 571(2):pp. 235-241

[5] Huang X, Qin F, Chen X, Liu Y and Zou H, Short columns with molecularly imprinted monolithic stationary phases for rapid separation of diastereomers and enantiomers, Journal of Chromatography B, 2004. 804(1):pp. 13 - 18

[6] Guiochon G, Monolithic columns in high-performance liquid chromatography, Journal of Chromatography A, 2007. 1168(1-2):pp. 101-168

[7] Buchmeiser MR, Polymeric monolithic materials: Syntheses, properties, functionalization and applications, Polymer, 2007. 48(8):pp. 2187-2198

[8] Zou H, Huang X, Ye M and Luo Q, Monolithic stationary phases for liquid chromatography and capillary electrochromatography, Journal of Chromatography A, 2002. 954(12):pp. 5-32

[9] Yang G, Liu H, Bai L, Jiang M and Zhu T, Preparation and characterization of novel poly (vinyl ester resin) monoliths, Microporous and Mesoporous Materials, 2008. 112(1-3):pp. 351-356

[10] Yan H and Row KH, Characteristics of a Monolithic Molecularly Imprinted Column and Its Application for Chromatographic Separation, Journal of Industrial and Engineering Chemistry, 2007. 13(4):pp. 552-557

[11] Huang X, Zou H, Chen X, Luo Q and Kong L, Molecularly imprinted monolithic stationary phases for liquid chromatographic separation of enantiomers and diastereomers, Journal of Chromatography A, 2003. 984(2):pp. 273-282

[12] Li H, Liu Y, Zhang Z, Liao H, Nie L and Yao S, Separation and purification of chlorogenic acid by molecularly imprinted polymer monolithic stationary phase, Journal of Chromatography A, 2005. 1098(1-2):pp. 66-74

[13] Jinno K, Watanabe H, Saito Y and Takeichi T, Capillary electrochromatography using fibers as stationary phases, Electrophoresis, 2001. 22(16):pp. 3371-3376

[14] Saito Y, Nakao Y, Imaizumi M, Takeichi T, Kiso Y and Jinno K, Fiber-in-tube solid-phase microextraction: a fibrous rigidrod heterocyclic polymer as the extraction medium, Fresenius' journal of analytical chemistry, 2000. 368(7):pp. 641-643
[15] Gong R, Hu Y, Chen J, Chen F and Liu Z, A cellulose-based carboxyl cotton chelator having citric acid as an anchored ligand: preparation and application as solid phase extractant for copper determination by flame atomic absorption spectrometry, Microchimica Acta, 2007. 158(3):pp. 315-320

[16] Gong R, Zhong K, Hu Y, Chen J and Zhu G, Thermochemical esterifying citric acid onto lignocellulose for enhancing methylene blue sorption capacity of rice straw, Journal of environmental management, 2008. 88(4):pp. 875-880

[17] Sungur Ş and Babaoğlu S, Synthesis of a new cellulose ion exchanger and use for the separation of heavy metals in aqueous solutions, Separation science and technology, 2005. 40(10):pp. 2067-2078

[18] Nasiruddin Khan M and Farooq Wahab M, Characterization of chemically modified corncobs and its application in the removal of metal ions from aqueous solution, Journal of hazardous materials, 2007. 141(1):pp. 237-244

[19] Wing R, Cellulosic citrates: preparation and ion exchange properties, Journal of Polymer Materials, 1997. 14(4):pp. 303-310

[20] Li X, Tang Y, Cao X, Lu D, Luo F and Shao W, Preparation and evaluation of orange peel cellulose adsorbents for effective removal of cadmium, zinc, cobalt and nickel, Colloids and Surfaces A: Physicochemical and Engineering Aspects, 2008. 317(1-3):pp. 512-521

[21] Wong KK, Lee CK, Low KS and Haron MJ, Removal of $\mathrm{Cu}$ and $\mathrm{Pb}$ by tartaric acid modified rice husk from aqueous solutions, Chemosphere, 2003. 50(1):pp. 23-28

[22] Vaughan T, Seo CW and Marshall WE, Removal of selected metal ions from aqueous solution using modified corncobs, Bioresource technology, 2001. 78(2):pp. 133-139

[23] Marshall W, Wartelle L, Boler D and Toles C, Metal ion adsorption by soybean hulls modified with citric acid: a comparative study, Environmental Technology, 2000. 21(6):pp. 601607

[24] Qin Y, Wang X and Wang ZL, Microfibre-nanowire hybrid structure for energy scavenging, Nature, 2008. 451(7180):pp. 809-813

[25] Burdick and Jackson, Solvent guide, Burdick and Jackson Laboratories, 1984

[26] Pellizzari E, Castillo N, Willis S, Smith D and Bursey J, Identification of organic components in aqueous effluents from energy-related processes, in Measurement of organic pollutants in water and wastewater: a symposium, Vol. 686, ASTM International, 1981. pp. 256-274

[27] Stankov IN, Yarova VA, Sergeeva AA, Potashova IV, Tarasov SN and Samofalova NN, Gas-chromatographic determination of monoethanolamine and its salts of inorganic and organophosphorus acids present in combination, Journal of Analytical Chemistry, 2000. 55(2):pp. 155-159

[28] Maham Y, Teng TT, Hepler LG and Mather AE, Volumetric properties of aqueous solutions of monoethanolamine, monoand dimethylethanolamines at temperatures from 5 to $80^{\circ} \mathrm{C}$, Thermochimica acta, 2002. 386(2):pp. 111-118

[29] Koda Y, Volumetric determination of pyridine bases using iron (III) hydroxide sulfate as indicator, Analytical Chemistry, 1970. 42(8):pp. 931-932

[30] Rao ALJ and Puri BK, Gravimetric, volumetric and conductometric determination of palladium with pyridine, Journal of Analytical Chemistry, 1970. 250(1):pp. 26-28

[31] Weiland R, Rawal M and Rice R, Stripping of carbon dioxide from monoethanolamine solutions in a packed column, AIChE Journal, 1982. 28(6):pp. 963-973

[32] Fleck HR, The detection and determination of triethanolamine, Analyst, 1935. 60(707):pp. 77-79

[33] Eastland C, Evers N and West T, A rapid method for the determination of triethanolamine, Analyst, 1937. 62(733):pp. 261266 